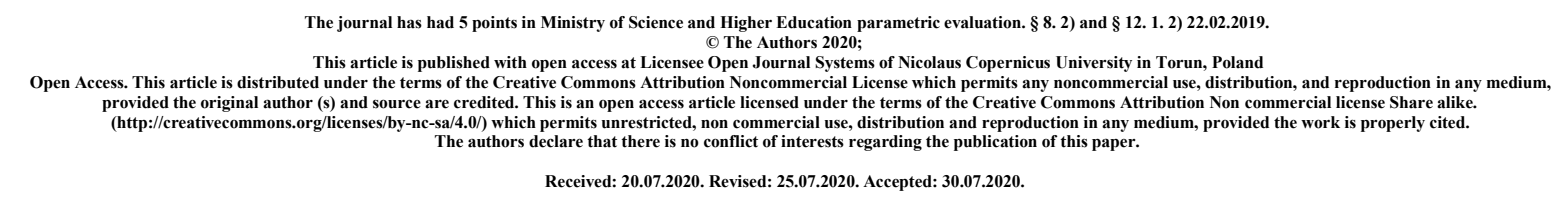

\title{
Are we still afraid of influenza during the Sars-Cov2 pandemic? - epidemiological analysis of influenza morbidity and vaccination in the $2019 / 2020$ season
}

\author{
Kinga Ruszel ${ }^{1}$, Halina Piecewicz-Szczęsna ${ }^{2}$ \\ ${ }^{1}$ Student Scientific Circle at the Chair and Department of Epidemiology and Clinical Research \\ Methodology, Medical University of Lublin \\ ${ }^{2}$ Chair and Department of Epidemiology and Clinical Research Methodology, \\ Medical University of Lublin
}

Corresponding author: Halina Piecewicz-Szczęsna, e-mail: halpiec@wp.pl

\section{ORCID ID:}

Kinga Ruszel orcid.org/0000-0002-9633-4288 kingaruszel@gmail.pl Halina Piecewicz-Szczęsna orcid.org/0000-0002-0573-7226, halpiec@gmail.com

\section{Summary:}

Influenza is an infectious respiratory disease that is caused by influenza A and B viruses in humans. Pandemic outbreaks mainly involve type A virus of zoonotic origin. The severity of the pandemic flu depends on many factors, including the virulence of the pandemic virus strain and the level of pre-existing immunity. Symptoms associated with influenza virus infection differ from mild respiratory disease limited to the upper respiratory tract and are characterized by fever, sore throat, runny nose, cough, headache, muscle pain and fatigue, as well as severe and in some cases fatal pneumonia due to influenza virus or secondary bacterial infection of the lower respiratory tract. The influenza virus is quite often subject to modifications, which makes it necessary to formulate an influenza vaccine every year to 
match the circulating strains. These vaccines are not mandatory and, despite the broadly understood promotion among the public, they are not widely purchased. In addition, the vaccine's effectiveness is quite low in the case of an antigenic mismatch between the vaccine and the circulating strain of the virus, which causes a still high level of illness during the year. In the 2019/2020 season, a significant decrease in the number of influenza cases was observed in Poland and in the world. In this work, we will take a closer look at the numerical values of people with influenza and discuss the possible causes of this decline. Did the Covid-19 pandemic favorably affect the incidence of another virus, such as the influenza virus, and cause its decline, or did it just overshadow the real numbers, put society to sleep, and diverted their attention?

Key words: influenza, vaccinations, epidemiology, prevention, morbidity

\begin{abstract}
Aim:
The purpose of the review is to summarize data on the incidence and possible mortality during the influenza season 2019/2020 and on the number of vaccinations performed at that time. It is worth adding about the restrictions on the availability of primary care physicians at the time due to the outbreak of the Sars-Cov2 virus, which may reduce the number of cases at the end of the season. It may be falsely underestimated. Therefore, influenza surveillance data should be interpreted with caution because the ongoing COVID-19 pandemic may have had a different impact on health behaviors, staff / procedures (including case definitions and sampling strategies). However, the various hygiene and physical distanceing measures implemented by Member States to reduce the transmission of SARS-CoV-2 virus may also have contributed to reducing the transmission of influenza virus.
\end{abstract}

\title{
Materials and methods:
}

PubMed databases and statistics from the National Institute of Public Health (PZH) and world data from WHO websites were searched in June and July 2020. The data are also provided remotely by National Influenza Centers (NICs) of the Global Influenza Surveillance and Response System ( GISRS) In the PubMed database we used any medical text and terms "flu", "influenza", "flu vaccine", "flu vaccination", "flu vaccine effectiveness". No language restrictions were added. 21 scientific articles published in the years 1980-2020 were scanned.

\section{Conclusions:}

Summing up, in the 2019/2020 season (September-April) the number of cases of influenza according to the WHO data was 1304 cases. Nevertheless, this number differs from the data from epidemiological reports published on the PZH website which indicate the number amounting to 338 cases. The number of deaths due to influenza between September 2019 and April 2020 was 64 people. They were mainly people over 65 years of age. 
All over the world, this season has been characterized mainly by influenza A viruses, the dominant subtype varies from country to country. Influenza A (H1N1) viruses pdm09 dominated or circulated together with influenza A (H3N2) viruses in most countries in North America, European transmission zones and in East and West Asia. Very low levels of antiviral resistance have been reported. Less genetic diversity was detected among influenza A (H1N1) viruses pdm09.

In conclusion, countries are encouraged to further improve and respond to influenza outbreaks and to prepare for a potential new pandemic despite a temporary fall in incidence, as the influenza virus is flexible and has a wide variety.

\section{Introduction:}

Influenza is an acute viral infection of the respiratory tract that spreads easily between people. In healthy people it is usually self-limiting, passes after about 3-7 days and does not cause complications. It can be particularly dangerous for children under 6 months of age and elderly people, as well as people with chronic diseases (such as chronic cardiac, pulmonary, renal, metabolic, neurodevelopmental, liver or hematologic diseases) and individuals with immunosuppressive conditions (such as HIV/AIDS, receiving chemotherapy or steroids, or malignancy). (1) We currently distinguish 4 types of influenza virus: A, B, C, D. (2-4) For people, the most important one is the enveloped type RNA influenza A virus, because it is the one which mainly causes infections in humans. Influenza A virus is also an important pathogen for many birds and mammals. All influenza viruses are surrounded by negativesense single-stranded RNA viruses with a segmented genome. Its superficial proteins, hemagglutinin and neuraminidase, are the main proteins used to identify it by the body. Thanks to them, the viral genome is activated in a mechanism dependent on the host cells. (5) Characteristic of influenza virus is its constant mutation and genome modification. Their segmented RNA genomes allow genetic re-sorting, and their RNA polymerase cannot be corrected, which leads to a high error rate. These traits lead to continuous evolution, host change events, escape from previous human population immunity ("antigenic drift"), new pandemics, and the development of antiviral drug resistance and the development of mutations with increased pathogenicity. The identification of virulence markers in influenza viruses forms the basis for risk assessment programs and the development of new therapeutic agents. All of this requires continuous molecular observation of the influenza virus and an annual update of influenza vaccines. (6)

\section{Epidemiology:}

The World Health Organization estimates that about one billion people are infected every year, about 3-5 million cases of serious illness and hospitalization occur, and 300,000 - 500,000 people die of flu each year. $(2,7)$ It is estimated that the total annual economic burden in the United States alone is USD 87.1 billion, which illustrates that influenza is both a social and economic problem. (8) Incidence of influenza causes a high rate of absenteeism at school and work, as well as significant costs of treatment and hospitalization. (9) There are probably even more cases of influenza, as the diagnosis is currently based mainly on respiratory symptoms, yet influenza can also cause symptoms from other systems. (8) Given the huge seasonal 
influenza burden in children and adults, it is important that both doctors and school nurses have knowledge of all aspects of this condition, including its clinical course and how it is transmitted, the range of prevention and treatment options and steps that can be taken to improve the percentage of immunization against influenza. (9)

In Poland:

Based on the data from NIZP-PZH in Poland in the years 2019/2020, a decrease in the incidence of influenza was observed compared to the 2017/2018 and 2019/2020 seasons. The numbers indicating people with suspected illness and confirmed case of influenza vary considerably, which is dictated by the number of tests performed, as well as an error in the clinical assessment of the patient by the doctor. (fig. 1) (10)

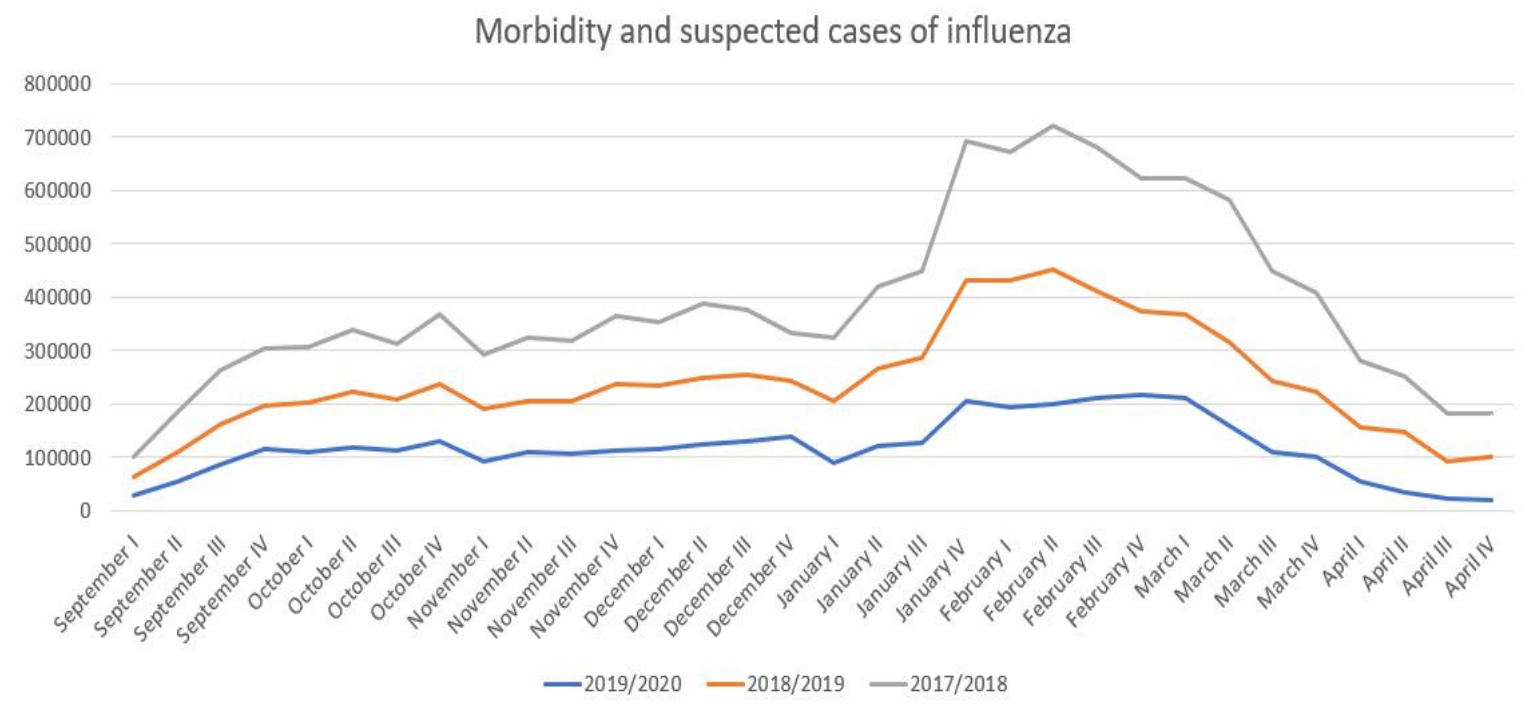

Figure 1. Morbidity and suspected cases od influenza - data base from the Polish National Hygiene Institute (PZH).

Data from NIZP-PZH differ from the data from the WHO website and are much lower. $(11,12)$ According to $\mathrm{PZH}$, the number of laboratory confirmed cases of influenza virus infections in Poland in the 2019/202 epidemic season are follows in table 1: (11)

\begin{tabular}{|c|c|c|c|}
\hline $\mathrm{A}$ & $\mathrm{A} / \mathrm{H} 1$ & $\mathrm{~A} / \mathrm{H} 3$ & $\mathrm{~B}$ \\
\hline 229 & 65 & 27 & 17 \\
\hline
\end{tabular}

Table 1. Source of PZH

According to WHO, the number of confirmed cases in Poland in the 2019/2020 season is 1304 cases of influenza. Total number of influenza positive viruses - 1304 (week 37 - 17) (12)

Despite the differences in the data, we can conclude that globally influenza activity was recorded at lower levels than expected for this time of the year.

\section{Symptoms:}


Influenza is an infectious mainly respiratory disease. Symptoms associated with influenza virus infection differ from mild respiratory disease. Common symptoms of uncomplicated influenza are fever, sore throat, runny nose, cough, headache, muscle pain and fatigue, and in some cases pneumonia due to influenza virus. In addition, secondary bacterial infection of the lower respiratory tract often occurs. (7) (fig. 2)

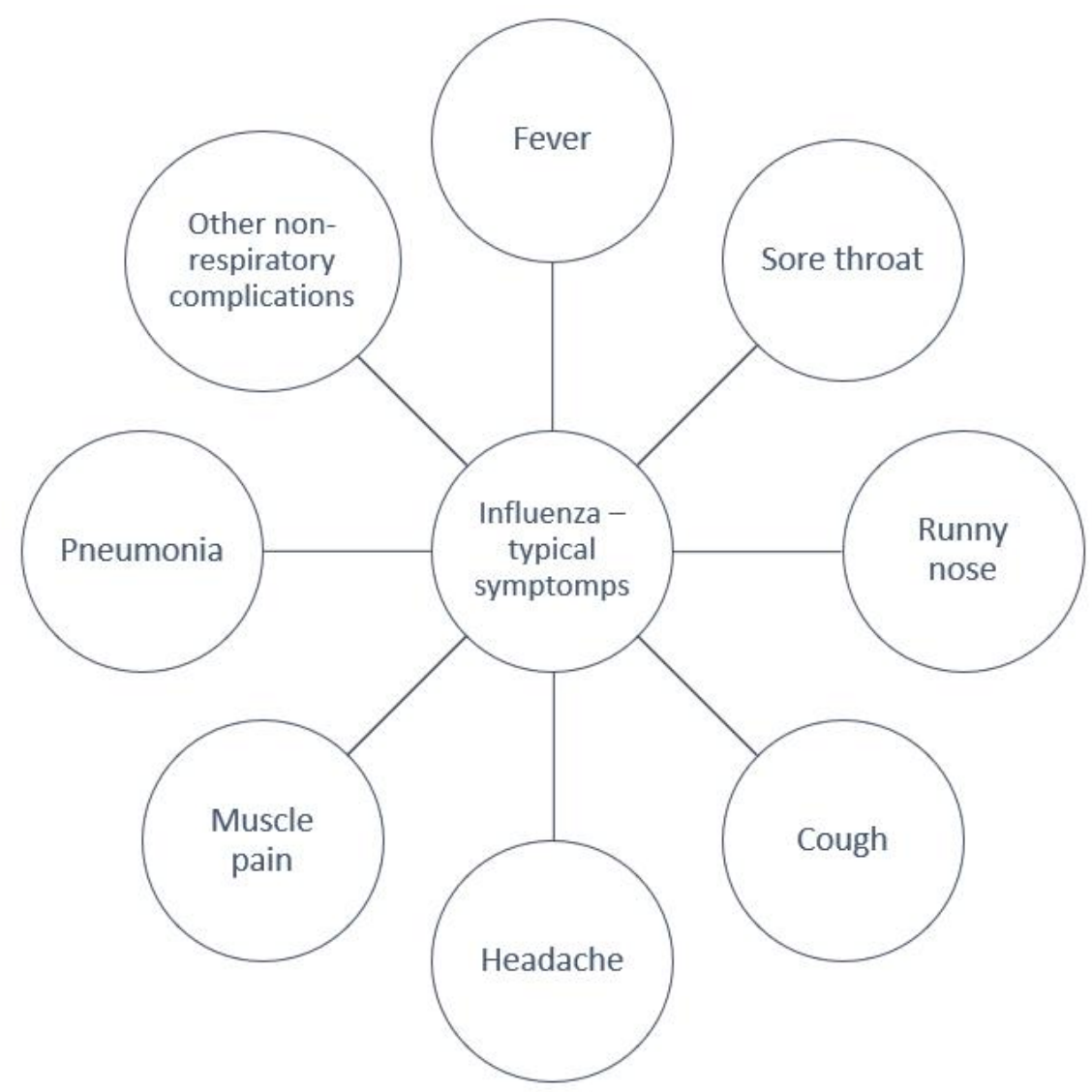

Figure 2. Typical symptomps of influenza

Severe influenza infection is a major cause of global morbidity and mortality. Although influenza is primarily considered a viral infection that results in respiratory restricted pathology, clinical reports suggest that influenza infection is often associated with many clinical syndromes involving non-respiratory tract systems, including the cardiovascular system, central nervous system . (tab. 2) The most commonly reported clinical entities were viral myocarditis, viral encephalitis, Guillain-Barre syndrome (GBS) and exacerbations of disease states, e.g. ischemic heart disease. Diagnosis of these extrapulmonary complications is critical to determine the true burden of influenza infection and initiating organ-specific supportive care. $(8,13)$ One patient may have multiple flu-related extrapulmonary complications at the same time.

Table 2. The most common extrapulmonary clinical syndromes occurring as a result of influenza virus infection

\begin{tabular}{|l|l}
\hline Organ system: & organ-specific terms:
\end{tabular} 


\begin{tabular}{|l|l|}
\hline Cardiac & $\begin{array}{l}\text { myocarditis, myocardial infarction, heart failure, cardiac ischemia, } \\
\text { cardiomiopathy, atrial fibrillation }\end{array}$ \\
\hline Neurologic & $\begin{array}{l}\text { encephalopathy, encephalitis, Guillain Barre syndrome, menigitis, } \\
\text { stroke, narcolepsy }\end{array}$ \\
\hline Hepatic & $\begin{array}{l}\text { hepatitis, liver disease, hepatic vein thrombus, portal vein } \\
\text { thrombus }\end{array}$ \\
\hline Renal & $\begin{array}{l}\text { acute kidney injury, glomerulonephritis, Goodpasture, } \\
\text { rhabdomyolisis, acute tubular necrosis }\end{array}$ \\
\hline Muscosceletal & Myositis, myopathy \\
\hline Ocular & optic neuritus, conjunctivitis, retinopathy \\
\hline Hematologic & $\begin{array}{l}\text { Leukopenia, lymphopenia, clot, thrombosis, embolism, hemolytic } \\
\text { uremic syndrome }\end{array}$ \\
\hline
\end{tabular}

Cardiovascular influenza complications:

Epidemiological studies have reported an increase in cardiovascular deaths during the influenza epidemic, which indicates that cardiovascular complications including exacerbation of heart failure, acute coronary heart disease and less frequently acute myocarditis are important contributors to morbidity and mortality. during flu infection. (14) Clinically diagnosed myocarditis has been reported in approximately $0.4 \%-13 \%$ of hospitalized adult patients with documented influenza. (15) In addition, influenza-related myocarditis often occurs alone without respiratory complications, since only about $40 \%$ of patients with myocarditis in one study also had documented pneumonia. (16) In one study published in 2009 by Japan, a retrospective national survey on H1N1pdm2009 myocarditis was performed to compare H1N1pdm2009 myocarditis in pandemic (2009/2010) and postpandemic (2010/2011) seasons, collecting data from 360 hospitals . Morbidity and mortality were found to be $28 \%$ (8/29) among all patients with myocarditis. This study also showed a high incidence of fulminant myocarditis (17/29, 59\%).

The relationship between different strains and subtypes of influenza and myocarditis is limited, and $70 \%$ relates to influenza A (H1N1). The clinical course of influenza-related myocarditis is variable and most patients experience an acute onset of symptoms associated with cardiac dysfunction, including dyspnoea, syncope, chest pain, hypotension and arrhythmias, usually between days 4 and 7 after the initial symptoms. viral infection. (17) Congestive heart failure diagnosed by echo / MRI is the most common complication and occurs in $84 \%$ of patients with influenza-related myocarditis. It may also be asymptomatic, suggesting that some patients with influenza infection may experience clinically unrecognized, asymptomatic myocardial damage. (18) In addition, during the epidemic periods a significant increase in the incidence and death due to coronary heart disease, myocardial infarction or atrial fibrillation was also detected. (13)

Stroke: 
The short-term risk of ischemic cerebral vascular accidents (CVA) or strokes appears to be significantly increasing during or shortly after a respiratory infection. It is worth noting that this risk does not increase after being influenza-based. (19)

To sum up, cardiovascular complications, mainly myocarditis, exacerbation of ischemic heart disease, and stroke have a significant impact on mortality from influenza infection.

Other important neurological complications are encephalitis, encephalopathy, Rey's syndrome, Guillain-Barre or Parkinson's. Neurological complications are more commonly reported in pediatric populations. $(20,21)$ In encephalopathy or influenza-related encephalitis (IAE), the rapid progress of consciousness disorders that occur within a few days of influenza infection is characteristic. Other less common symptoms included urinary retention, blindness, hemiparesis, cerebellar symptoms and opisthotonus. (20) The pathogenesis of encephalopathy and influenza-associated encephalitis remains undetermined. Demonstration of viral RNA detected by rRT-PCR in brain tissue and CSF suggests a direct viral invasion of CNS. Nevertheless, IAE patients are more likely to experience concomitant hepatic and renal dysfunction, which may suggest the coexistence of metabolic encephalopathy with severe influenza disease rather than as a direct effect of the virus itself. $(22,23)$

Reye's syndrome is a rapidly progressing disease that is now increasingly rare, characterized by encephalopathy and fatty liver infiltration, associated with viral infections, including flu treated with acetylsalicylic acid. It was mainly seen in children. Since the recognition of the role of acetylsalicylic acid in Rey's syndrome, the incidence of cases reported has dropped dramatically due to the avoidance of aspirin in the treatment of viral infections. (24)

Other less common but also occurring of influenza are listed in the table (Table 1).

\section{Treatment and prevention of influenza:}

All patients in the course of influenza are treated symptomatically, and in the case of complications and the occurrence of a severe or progressive disease with confirmation of infection with influenza virus (i.e. clinical syndromes of pneumonia, sepsis or exacerbation of chronic underlying diseases) neuraminidase inhibitors are applied, including oseltamivir, peramivir and / or zanamivir (preferably within 48 hours of onset of symptoms). Treatment is recommended for at least 5 days, but it can be extended until a satisfactory clinical improvement is achieved. Depending on the patient's condition in clinical practice, they can additionally be treated with corticosteroids and have even plasma replacement taken into consideration, but this is not a routine treatment. $(2,13)$

Nevertheless, it is important to prevent influenza. It is important to remember about the annual vaccination against influenza, the hygiene of washing and disinfecting the hands and covering the mouth and nose when coughing and sneezing. Currently, such treatments also help in fighting Sars-Cov2 infection. During the flu season, avoid staying in rooms with high density of people and people with symptoms of upper respiratory tract infection. (10) 


\section{Vaccinations for influenza:}

Given the relationship between peak influenza activity and cardiovascular events, research has increasingly assessed the impact of vaccination against influenza on reducing cardiovascular disease. It was concluded that the incidence of acute myocardial infarction was significantly reduced within 60 days after vaccination against influenza, and this effect was most pronounced in the first 2 weeks after vaccination with a $32 \%$ reduction in acute myocardial infarction 25-59 days after vaccination. (25)

Among older people, influenza vaccination may be less effective in preventing disease, but it reduces the severity of the disease and the incidence of complications and deaths. Vaccinations are particularly important for people who are at high risk of flu complications and for people who live with or care for high-risk people. WHO recommends annual vaccination

for:

1. pregnant women at any stage of pregnancy

2. children from 6 months to 5 years old

3. elderly people (over 65 years of age)

4. people with chronic illnesses

5. health care professionals. $(2,10)$

The National Institute of Public Health - PZH does not have data on vaccinations in 2019 and 2020 in its database. The number of vaccinations in 2018 was 42474 in the first half of the year and 966811 in the second half, which gave a total of 1009285 vaccinations in 2018, with the highest percentage of vaccinated persons aged $65+$, however, this number was only slightly higher than the number of vaccinations aged 15-64. (26)

\section{Conclusions:}

In summary, countries are encouraged to continue to improving and responding to influenza outbreaks and to prepare for a potential new pandemic despite a temporary fall in incidence, as the influenza virus is flexible and highly diverse. Efforts should be made to vaccinate people who are particularly vulnerable and with indications for such vaccination. Despite the growing vaccination movements, society should be encouraged and ideas for preventing influenza epidemics should be promoted.

\section{Funding:}

This research received no external funding.

\section{Conflicts of Interest}


The authors declare no conflict of interest

\section{Bibliography:}

1. Ghebrehewet S, MacPherson P, Ho A. Influenza. BMJ [Internet]. 7 grudzień 2016 [cytowane 9 lipiec 2020];355. Dostępne https://www.ncbi.nlm.nih.gov/pmc/articles/PMC5141587/

2. Influenza (Seasonal) [Internet]. [cytowane 9 lipiec 2020]. Dostępne na: https://www.who.int/news-room/fact-sheets/detail/influenza-(seasonal)

3. Hause BM, Collin EA, Liu R, Huang B, Sheng Z, Lu W, i in. Characterization of a novel influenza virus in cattle and Swine: proposal for a new genus in the Orthomyxoviridae family. mBio. 4 marzec 2014;5(2):e00031-00014.

4. Su S, Fu X, Li G, Kerlin F, Veit M. Novel Influenza D virus: Epidemiology, pathology, evolution and biological characteristics. Virulence. 17 2017;8(8):1580-91.

5. Taubenberger JK. Influenza's Newest Trick. mBio [Internet]. 24 grudzień 2019 [cytowane 9 lipiec 2020];10(6). Dostępne na: https://mbio.asm.org/content/10/6/e02854-19

6. Kwon H, Kim Y-I, Park S-J, Kim E-H, Kim S, Si Y-J, i in. A Novel NeuraminidaseDependent Hemagglutinin Cleavage Mechanism Enables the Systemic Spread of an H7N6 Avian Influenza Virus. mBio [Internet]. 24 grudzień 2019 [cytowane 9 lipiec 2020];10(6). Dostępne na: https://mbio.asm.org/content/10/6/e02369-19

7. Krammer F, Smith GJD, Fouchier RAM, Peiris M, Kedzierska K, Doherty PC, i in. Influenza. Nature Reviews Disease Primers. 28 czerwiec 2018;4(1):1-21.

8. Molinari N-AM, Ortega-Sanchez IR, Messonnier ML, Thompson WW, Wortley PM, Weintraub $\mathrm{E}, \mathrm{i}$ in. The annual impact of seasonal influenza in the US: measuring disease burden and costs. Vaccine. 28 czerwiec 2007;25(27):5086-96.

9. Li C, Freedman M. Seasonal influenza: an overview. J Sch Nurs. luty 2009;25 Suppl $1: 4 \mathrm{~S}-12 \mathrm{~S}$.

10. Zachorowania na grypę w Polsce [Internet]. [cytowane 14 lipiec 2020]. Dostępne na: http://wwwold.pzh.gov.pl/oldpage/epimeld/grypa/index.htm

11. Zachorowania i podejrzenia zachorowań na grypę w Polsce, 2020, 4D (16). 2020;4.

12. WHO FLUMART OUTPUTS [Internet]. [cytowane 14 lipiec 2020]. Dostępne na: https://apps.who.int/flumart/Default?ReportNo=12

13. Sellers SA, Hagan RS, Hayden FG, Fischer WA. The hidden burden of influenza: A review of the extra-pulmonary complications of influenza infection. Influenza Other Respir Viruses. 2017;11(5):372-93. 
14. Warren-Gash C, Hayward AC, Hemingway H, Denaxas S, Thomas SL, Timmis AD, i in. Influenza infection and risk of acute myocardial infarction in England and Wales: a CALIBER self-controlled case series study. J Infect Dis. 1 grudzień 2012;206(11):1652-9.

15. Kodama M. Influenza Myocarditis. Circulation Journal. 2010;advpub:10090808911009080891.

16. Ukimura A, Ooi Y, Kanzaki Y, Inomata T, Izumi T. A national survey on myocarditis associated with influenza H1N1pdm2009 in the pandemic and postpandemic season in Japan. Journal of Infection and Chemotherapy. 1 styczeń 2013;19(3):426-31.

17. Onitsuka H, Imamura T, Miyamoto N, Shibata Y, Kashiwagi T, Ayabe T, i in. Clinical manifestations of influenza a myocarditis during the influenza epidemic of winter 1998-1999. J Cardiol. czerwiec 2001;37(6):315-23.

18. Kaji M, Kuno H, Turu T, Sato Y, Oizumi K. Elevated serum myosin light chain I in influenza patients. Intern Med. lipiec 2001;40(7):594-7.

19. Smeeth L, Thomas SL, Hall AJ, Hubbard R, Farrington P, Vallance P. Risk of myocardial infarction and stroke after acute infection or vaccination. $\mathrm{N}$ Engl J Med. 16 grudzień 2004;351(25):2611-8.

20. Bartynski WS, Upadhyaya AR, Boardman JF. Posterior Reversible Encephalopathy Syndrome and Cerebral Vasculopathy Associated With Influenza A Infection: Report of a Case and Review of the Literature. Journal of Computer Assisted Tomography. grudzień 2009;33(6):917-922.

21. Studahl M. Influenza virus and CNS manifestations. Journal of Clinical Virology. 1 grudzień 2003;28(3):225-32.

22. Fujimoto S, Kobayashi M, Uemura O, Iwasa M, Ando T, Katoh T, i in. PCR on cerebrospinal fluid to show influenza-associated acute encephalopathy or encephalitis. The Lancet. 12 wrzesień 1998;352(9131):873-5.

23. Steininger C, Popow-Kraupp T, Laferl H, Seiser A, Gödl I, Djamshidian S, i in. Acute encephalopathy associated with influenza A virus infection. Clin Infect Dis. 1 marzec 2003;36(5):567-74.

24. Davis LE, Kornfeld M. Influenza A virus and Reye's syndrome in adults. J Neurol Neurosurg Psychiatry. czerwiec 1980;43(6):516-21.

25. Siriwardena AN, Gwini SM, Coupland CAC. Influenza vaccination, pneumococcal vaccination and risk of acute myocardial infarction: matched case-control study. CMAJ. 19 październik 2010;182(15):1617-23.

26. SZCZEPIENIA OCHRONNE W POLSCE W 2018 ROKU. :102. 